\title{
The relatively high frequency of p53 gene mutations in multiple and malignant phaeochromocytomas
}

\author{
T Yoshimoto, M Naruse, Z Zeng ${ }^{5}$, T Nishikawa ${ }^{1}$, T Kasajima $^{2}$, \\ H Toma ${ }^{3}$, S Yamamori ${ }^{4}$, H Matsumoto ${ }^{4}$, A Tanabe, K Naruse and \\ H Demura
}

Department of Medicine, Institute of Clinical Endocrinology, ${ }^{1}$ Department of Surgical Pathology, ${ }^{2}$ Department of Pathology, ${ }^{3}$ Department of Urology, Tokyo Women's Medical University, Tokyo 162, Japan, ${ }^{4}$ Mitsubishikagaku BCL Co. Ltd, Tokyo 174-0056, Japan and ${ }^{5}$ Department of Endocrinology, Peking Union Medical College, Beijing, China

(Requests for offprints should be addressed to T Yoshimoto, Department of Medicine, Institute of Clinical Endocrinology, Tokyo Women's Medical University, 8-1 Kawadacho, Shinjuku-ku, Tokyo 162, Japan)

\begin{abstract}
To explore the clinical significance of p53 in the pathogenesis of adrenal neoplasms, we investigated the incidence of p53 gene mutations in functioning human adrenal tumours using the polymerase chain reactionsingle strand conformation polymorphism (PCR-SSCP) technique to screen p53 exons 4 to 9 . We examined 29 adrenocortical adenomas (primary aldosteronism, $n=17$; Cushing's syndrome, $n=12$, all benign), and 33 phaeochromocytomas (benign solitary, $n=18$; benign multiple, $n=5$; malignant, $n=10)$ in Japanese and Chinese patients. PCR-SSCP did not show any abnormal band-shifts in any of the adrenocortical adenoma and benign solitary phaeochromocytoma tissues. In contrast, six phaeochromocytoma tissues (two cases benign multiple, four cases malignant) showed PCR-SSCP band-shifts. Subsequent DNA sequencing analysis of the shifted bands revealed six cases with nine mutations or intronic sequence alterations:
\end{abstract}

three cases contained sequence alterations within intronic regions, three cases with silent mutation (sequence alteration in codon without amino acid alteration), and three cases contained missense mutations (one case each in exons 5, 6 and 9). Immunohistochemical staining demonstrated that two of three cases with missense mutations and one case with an intronic sequence alteration over-expressed p53 protein in tumour cell nuclei. We observed no association between p53 gene mutation and p21/WAF1/ Cip-1 expression. The relatively high incidence of $\mathrm{p} 53$ gene mutations or intronic sequence alteration in multiple and malignant phaeochromocytomas, but not in benign solitary cases, suggests that p53 mutation could play some role in the pathogenesis of multiple and/or malignant phaeochromocytomas.

Journal of Endocrinology (1998) 159, 247-255

\section{Introduction}

Mutation of the tumour suppressor gene p53, located on chromosome $17 \mathrm{p}$, has an important role in tumorgenesis and/or progression of various types of human neoplasma (Hollstein et al. 1991, Greenblatt et al. 1994, Velculescu \& El-Deiry 1996). The majority of p53 mutations occur in four highly conserved domains, or 'hot spots', located in exons 5 to 8 (Greenblatt et al. 1994, Velculescu \& El-Deiry 1996). Germline mutations of the p53 gene have been identified in Li-Fraumeni syndrome, a rare familial syndrome with a high incidence of diverse cancers including adrenocortical carcinoma (Hollstein et al. 1991). The loss of heterozygosity at chromosome $17 \mathrm{p}$ shown in a number of phaeochromocytoma and adrenal carcinoma cases suggests some role of p53 in the tumorgenesis of adrenal tissues (Yano et al. 1989, Khosla et al. 1991). However, Yoshimoto et al. (1992) found no evidence of p53 gene mutations in 11 cases of adrenocortical adenoma and 17 cases of phaeochromocytoma. Reincke et al. (1994) reported p53 mutations in 3 of 11 cases of adrenocortical carcinoma but not in cases of adrenocortical adenoma.

More recently, Lin et al. (1994) found 11 of 15 cases of adrenocortical adenoma (13 primary aldosteronism, 2 Cushing's syndrome) and 5 of 6 cases of phaeochromocytoma in Taiwanese patients contained p53 gene mutations, $75 \%$ of which were clustered in exon 4 . These results suggested that $\mathrm{p} 53$ gene mutation was pathophysiologically significant in the tumorgenesis of benign functioning adrenal tumours, with exon 4 as a new mutational 'hot spot'. However, Dahia et al. (1995) reported that there was no p53 gene mutation encompassing exons 4-8 in 25 phaeochromocytomas. Reincke et al. (1996) also found no mutations in exon 4 of the p53 gene in 19 cases of adrenocortical adenoma and six cases of phaeochromocytoma in patients from the USA and Europe. Although 
Table 1 Age (mean \pm S.E.M.), sex, diagnosis, pathology, and ethnic data of the patients studied

\begin{tabular}{|c|c|c|c|c|c|}
\hline & Number of patients & Age & Gender & Histology & Race \\
\hline Primary aldosteronism & 17 & $37 \cdot 1 \pm 3 \cdot 7$ & M9/F8 & All CA & J11/C6 \\
\hline Cushing's syndrome & 12 & $35 \cdot 4 \pm 3 \cdot 1$ & $\mathrm{M} 1 / \mathrm{F} 11$ & All CA & J12 \\
\hline Phaeochromocytoma & 33 & $42 \cdot 9 \pm 2 \cdot 3$ & $\mathrm{M} 17 / \mathrm{F} 16$ & Phaeo & $\mathrm{J} 21 / \mathrm{C} 12$ \\
\hline Benign solitary & 18 & $43 \cdot 7 \pm 2 \cdot 9$ & $\mathrm{M} 12 / \mathrm{F} 6$ & Phaeo & J9/C9 \\
\hline Benign multiple & 5 & $38 \cdot 0 \pm 7 \cdot 1$ & $\mathrm{M} 1 / \mathrm{F} 4$ & Phaeo & $\mathrm{J} 5$ \\
\hline Malignant & 10 & $42 \cdot 9 \pm 4 \cdot 8$ & M4/F6 & Phaeo & $\mathrm{J} 7 / \mathrm{C} 3$ \\
\hline
\end{tabular}

M, male; F, female; CA, cortical adenoma; Pheo, phaeochromocytoma; J, Japanese patient; C, Chinese patient.

the reasons for this discrepancy have not been determined, ethnic and geographic factors may be responsible. In addition, a proportion of phaeochromocytoma cases occur as multiple or malignant tumours. The pathophysiological significance of p53 gene mutation in these cases remains to be elucidated.

In the present study, we investigated mutation in the p53 gene between exons 4 and 9 in a total of 62 cases of functioning adrenal tumours in patients from Japan and China.

\section{Materials and Methods}

\section{Human adrenal tumour tissue samples}

Sixty-four specimens from sixty-two patients with adrenal tumours were studied. Fifty-two were frozen samples and twelve were formalin-fixed paraffin-embedded samples. As shown in Table 1, the adrenal tumour specimens consisted of 17 cases of primary aldosteronism, 12 cases of Cushing's syndrome (all benign adrenocortical adenoma), and 33 cases of phaeochromocytomas (benign solitary, $n=18$; benign multiple, $n=5$; malignant, $n=12$ (12 specimens from 10 cases)). Diagnosis was made by clinical and histological findings following standardized criteria (Landsberg \& Young 1992, Orth et al. 1992) at Tokyo Women's Medical College Hospital for Japanese patients and at Peking Union Medical College Hospital for Chinese patients. Phaeochromocytoma with metastatic lesions was considered as malignant. Multicentric phaeochromocytoma derived from chromaffin tissues was considered to be benign multiple tumour. In two patients with malignant phaeochromocytoma, two tumour tissues were analysed (cases 25 and 32); the first tissue specimens, $25-1$ and $32-1$, were obtained at the time of initial adrenal surgery when the tumour was diagnosed as benign, while the second tissue specimens were obtained by autopsy four years (25-2) and 12 years (32-2) after surgery when the tumour was diagnosed as malignant.

The present study was approved by the Ethics Committee of the Tokyo Women's Medical College.

\section{Extraction of DNA}

For paraffin-embedded specimens, two or three pieces of $10 \mu \mathrm{m}$ sections were carefully cut and placed in sterile microfuge tubes, deparaffinized by washing twice in xylene, and twice in 99.5\% ethanol and finally dried briefly under reduced pressure. DNA was extracted from $20 \mathrm{mg}$ frozen tissue specimens or deparaffinized specimens according to the proteinase $\mathrm{K}$ digestion method and subsequent spin-column purification using QIAamp Tissue Kits (QIAGEN, Hilden, Germany). Fifty nanograms DNA from each frozen tissue specimen was used for polymerase chain reaction-single strand conformation polymorphism (PCR-SSCP). For paraffin-embedded specimens, the eluted DNA solution was precipitated by ethanol and redissolved in $5 \mu 10 \mathrm{mmol} / 1$ Tris- $\mathrm{HCl}(\mathrm{pH}$ 7.6). One microlitre DNA solution was used as the template for PCR-SSCP.

\section{PCR-SSCP analysis}

PCR-SSCP analysis was performed to screen for p53 gene mutations in the adrenal tumour tissues. As shown in Table 2, seven primer sets for exons 4-9 were designed according to published p53 nucleotide sequences (Futreal et al. 1991). In order to amplify entire exonic sequences each set of primers was designed to anneal to intronic sequences. As exon 4 is too long for PCR-SSCP analysis,

Table 2 Nucleotide sequence of primers used for the PCR-SSCP analysis and DNA sequencing

\section{Sequence}

\begin{tabular}{ll}
\cline { 2 - 2 } Exon & \\
$4-1$ & S, 5'-TGCCGTCCCAAGCAATGGAT-3' \\
$4-2$ & A, 5'-CTGGGAAGGGACAGAAGATGA-3' \\
& S, 5'-GTGGCCCCTGCACCAGCAGCT-3' \\
& A, 5'-AGGCATGAAGTCTCATGGA-3' \\
5 & S, 5'-TGTTCACTTGTGCCCTGACT-3' \\
& A, 5'-CAGCCCTGTCGTCTCTCCAG-3' \\
6 & S, 5'-GCCTCTGATTCCTCACTGAT-3' \\
& A, 5'-TTAACCCCTCCTCCCAGAGA-3' \\
7 & S, 5'-ACTGGCCTCATCTTGGGCCT-3' \\
& A, 5'-TGTGCAGGGTGGCAAGTGGC-3' \\
8 & S, 5'-TAAATGGGACAGGTAGGACC-3' \\
& A, 5'-TCCACCGCTTCTTGTCCTGC-3' \\
9 & S, 5'-ACTAAGCGTGGTAAGCAAGC-3' \\
& A, 5'-CTGGAAACTTCCACTTGAT-3'
\end{tabular}

S, sense primer; A, antisense primer. Exon 4 is divided into two parts (exon 4-1 and exon 4-2), since it has too long a sequence for PCR-SSCP analysis. 
it was divided into two parts (exon 4-1: codons 33-100; exon 4-2: codons 73-125). PCR of exons 4 to 9 was performed with the use of a thermal cycler (Model 480, Perkin-Elmer, Norwalk, CT, USA). Twenty-five microlitres PCR reaction mixture containing template DNA, 6.25 pmol of each primer, $1 \mathrm{U}$ Taq DNA polymerase (Perkin-Elmer), $10 \mathrm{mmol} / 1$ Tris-HCl (pH 8.3), $50 \mathrm{mmol} / 1 \mathrm{KCl}, 1.5 \mathrm{mmol} / 1 \mathrm{MgCl}_{2}, 0.01 \%$ gelatin, $50 \mu \mathrm{mol} / 1$ of each dNTP, and $0.5 \mu \mathrm{l} \quad\left[\alpha{ }^{32} \mathrm{P}\right] \mathrm{dCTP}$ $(3000 \mathrm{Ci} / \mathrm{mmol}, 10 \mathrm{mCi} / \mathrm{ml}$; New England Research Products, Boston, MA, USA) were incubated for $5 \mathrm{~min}$ at $95{ }^{\circ} \mathrm{C}$ for denaturation and followed by $30-40$ cycles consisting of $1 \mathrm{~min}$ denaturation at $94^{\circ} \mathrm{C}, 1 \mathrm{~min}$ annealing at $55{ }^{\circ} \mathrm{C}$ and $1 \mathrm{~min}$ polymerization at $72^{\circ} \mathrm{C}$. Each PCR product was diluted in a denaturation solution containing $20 \mathrm{mmol} / 1 \mathrm{EDTA}, 96 \%$ formamide, $0 \cdot 05 \%$ xylene-cyanol, and $0.05 \%$ bromophenol blue, heat-denaturated, and loaded onto $5 \%$ polyacrylamide gels containing 5\% glycerol. After electrophoresis, the gel was transferred to Whatman 3MM paper, vacuum-dried, and exposed at $-80{ }^{\circ} \mathrm{C}$ for $1-8 \mathrm{~h}$ for autoradiography.

\section{Direct sequencing of PCR products}

Abnormal bands detected by PCR-SSCP analysis were excised from the dried gel, placed in $100 \mu \mathrm{l}$ distilled water in a microfuge tube for $2 \mathrm{~h}$ at room temperature. Five microlitres supernatant was used as the DNA template in a PCR reaction. Twenty-five microlitres PCR reaction mixtures containing template DNA, $6.25 \mathrm{pmol}$ of each primer, $1 \mathrm{U}$ Taq DNA polymerase (Perkin-Elmer), $10 \mathrm{mmol}$ Tris $-\mathrm{HCl}$ (pH 8.3), $50 \mathrm{mmol} \mathrm{KCl}, 1.5 \mathrm{mmol}$ $\mathrm{MgCl}_{2}, 0 \cdot 01 \%$ gelatin and $200 \mu \mathrm{mol}$ of each dNTP were incubated for $5 \mathrm{~min}$ at $95^{\circ} \mathrm{C}$ for denaturation and followed by 30 cycles of $1 \mathrm{~min}$ denaturation at $94^{\circ} \mathrm{C}, 1 \mathrm{~min}$ annealing at $55^{\circ} \mathrm{C}$ and $1 \mathrm{~min}$ polymerization at $72{ }^{\circ} \mathrm{C}$. The PCR products were electrophoresed in $1.5 \%$ lowmelting-temperature agarose gels (Nusieve GTG Agarose, Bio-Rad Laboratories, Richmond, CA, USA), isolated and purified by standard methods (Sambrook et al. 1989). Sequencing reactions using purified PCR products were performed by the dye terminator cycle sequence method using the Dye Terminator Cycle Sequencing Kit (Perkin-Elmer) in a thermal-cycler (Model 480, PerkinElmer). The reactions were then applied to an automated DNA sequencer (Applied Biosystems Inherit, PRISM model 377 DNA sequencer, Perkin-Elmer).

\section{Immunohistochemical staining of $p 53$ and p21/WAF1/Cip1}

Immunohistochemical analysis of p53 and p21/WAF1/ Cip1, one of the major downstream factors of $\mathrm{p} 53$ (Velculescu \& El-Deiry 1996), was carried out using formalin-fixed paraffin-embedded sections of p53 mutation- or intronic sequence alteration-positive specimens identified by PCR-SSCP and subsequent DNA sequencing. Anti-p53 monoclonal antibody DO-7 (Vojtesek et al. 1992) (dilution of 1:50, DAKO, Carpinteria, CA, USA) and anti-p21/WAF1/Cip1 monoclonal antibody EA-10 (El-Deiry et al. 1995) (dilution of 1:20, Calbiochem-Novabiochem International, Cambridge, MA, USA) were used for detection. Sections $(5 \mu \mathrm{m})$ were deparaffinized, rehydrated, and incubated with phosphate-buffered saline (PBS) containing 1\% bovine serum albumin for $15 \mathrm{~min}$ at room temperature. Sections were incubated with primary antibodies for $12 \mathrm{~h}$ at $4{ }^{\circ} \mathrm{C}$. The antibody binding was visualized by the avidin-biotin-complex-peroxidase method using Vectastain ABC kits (Vector Laboratories, Burlingame, CA, USA).

\section{Results}

\section{PCR-SSCP analysis and DNA sequencing}

As shown in Figs 1-3, 6 of 35 phaeochromocytoma specimens showed abnormal band-shifts: case 14 (exon 9, Chinese, malignant), case 20 (exon 5, Japanese, benign multiple), case 24 (exon 8, Japanese, malignant), case 25-2 (exon 4 and 9, Japanese, malignant), case 26 (exon 6, Japanese, benign multiple), and case 32-2 (exon 9, Japanese, malignant). In two patients with malignant phaeochromocytomas, the abnormal band-shifts were observed in the autopsy specimens (25-2 and 32-2), but not in specimens obtained from the initial adrenal surgery (25-1 and 32-1) (Figs 1, 3). As shown in Table 3, subsequent DNA sequencing of the altered p53 PCRSSCP bands revealed sequence alterations in all six cases. Sequence alterations were found in introns in 3 cases (14, $25-2,32-2)$ and in exons in 4 cases $(20,24,25-2,26)$. Of the sequence alterations occurring in exonic regions, three cases $(20,25-2,26)$ showed missense mutations and two cases $(24,25-2)$ showed silent mutations (i.e. sequence alteration without amino acid alteration). All observed sequence alterations were transitions; we observed one case (20) of an A:T to G:C transition, the remaining five cases $(14,24,25-2,26,32-2)$ being $G: C$ to A:T transitions.

In total, we observed p53 gene mutations or intronic sequence alterations in 2 of $5(40 \%)$ benign multiple cases and 4 of $10(40 \%)$ malignant cases of phaeochromocytoma. In contrast, no p53 gene mutations or intronic sequence alterations were found in 18 cases of benign solitary phaeochromocytomas, 17 cases of primary aldosteronism and 12 cases of Cushing's syndrome.

In agreement with previous reports (Buchman et al. 1988, Dahia et al. 1995, Reincke et al. 1996), we observed an exon 4 polymorphism at codon 72 (proline (CCC) or arginine $(C G C))$ in the adrenal tumour specimens in the present study. The polymorphism was detected by PCRSSCP and confirmed by DNA sequencing. An example of our results is shown in Fig. 1a, lane 2 of this figure 


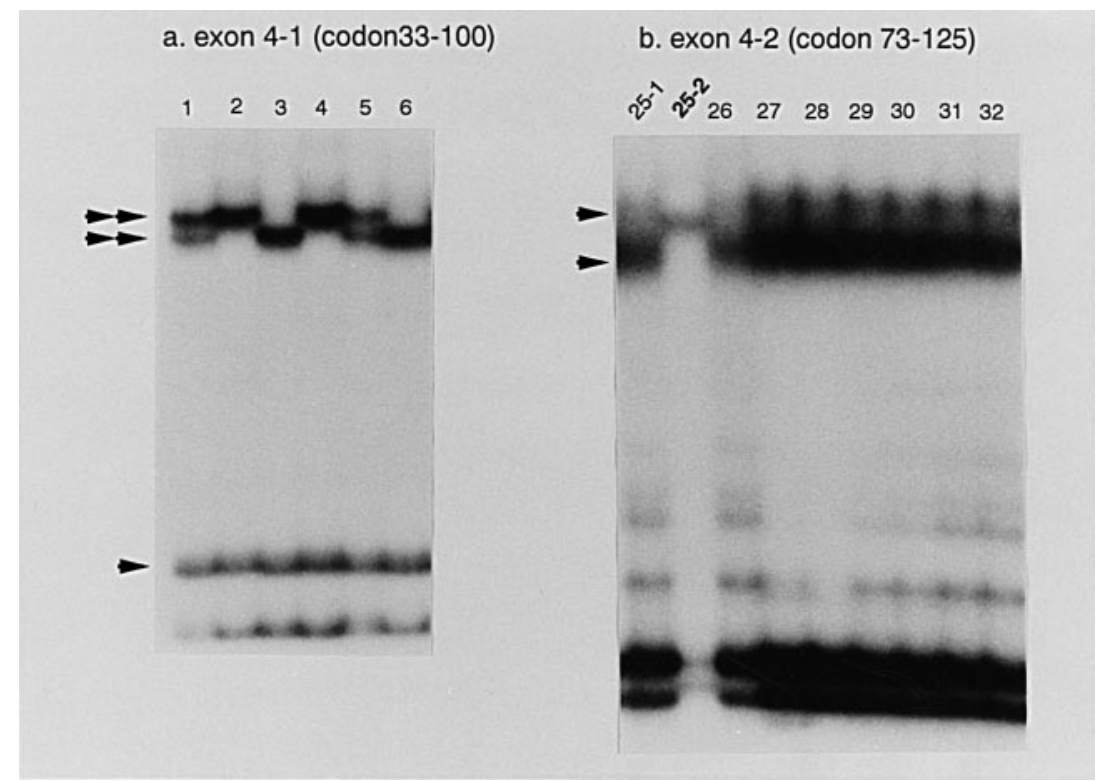

Figure 1 PCR-SSCP analysis of p53 gene mutation in (a) exon 4-1 (codons 33-100) and (b) exon 4-2 (codons 73-125) in phaeochromocytoma. Each arrow head represents the single stranded band observed after polyacrylamide gel electrophoresis. The lane number represents the specimen number from 32 cases of phaeochromocytoma. Lanes with abnormal band-shifts are indicated by bold characters. Double arrow heads signify codon 72 polymorphism in exon 4-1. Lane 2 indicates proline (CCC), lane 3 indicates arginine (CGC), and lane 1 indicates heterozygous proline and arginine.

indicates a proline (CCC), lane 3 indicates an arginine (CGC) while lane 1 indicates a heterozygous proline and arginine at codon 72 . However, there was no significant difference in the frequency of this polymorphism between the three kinds of adrenal tumours.

\section{Immunohistochemical staining of $p 53$ and p21/WAF1/Cip1 protein}

Immunohistochemical analysis of p53 and the p21/ WAF1/Cip1 protein was performed in five specimens of phaeochromocytoma which showed p53 gene mutations or intronic sequence alterations (cases 20, 24, 25-2, 26, 32-2). Five specimens of benign solitary phaeochromocytoma with normal p53 genes were also analyzed. As shown in Table 3, over-expression of $\mathrm{p} 53$ protein was found in three of five specimens with p53 gene mutation or intronic sequence alterations (one of two benign multiple cases, and two of three malignant cases). Examples of the positive staining are shown in Fig. 4a,b. No obvious nuclear staining was seen in specimens without p53 gene mutation as shown in Fig. 4c (case 4, benign solitary case). In contrast to $\mathrm{p} 53, \mathrm{p} 21 / \mathrm{WAF} 1 / \mathrm{Cip} 1$ was poorly expressed despite the presence of mutated p53 (Table 3). Immunohistochemical staining of p21/WAF1/Cip1 was seen only in scattered cells (Fig. 5: (a) cases 26 and (b) 32-2 with p53 gene mutations or intronic sequence alterations; (c) case 1 with benign solitary tumour without gene mutation).

\section{Discussion}

Lin et al. (1994) described frequent mutations in exon 4 of the p53 gene as a new 'hot-spot' in Taiwanese patients with functioning adrenocortical tumours. However, no such mutations were found in adrenal tumours of patients from the USA and Europe (Reincke et al. 1996). Since racial differences have been suggested as an explanation for this discrepancy, we analyzed tissue specimens from Japanese and Chinese patients. We found no p53 gene mutations within exons 4 to 9 in a total of 29 cases of functioning adrenocortical adenoma, either primary aldosteronism $(n=17)$ or Cushing's syndrome $(n=12)$. It is therefore unlikely that the presence of the new hotspot is due simply to ethnic differences. As the Chinese patients used in this present study were from the northern part of China, and patients studied in Lin's report were from Taiwan, geographic factors cannot be excluded completely. Nonetheless, this present study suggests that p53 gene mutations are not important factors in the tumorgenesis of adrenocortical adenoma.

In agreement with previous studies (Yana et al. 1992, Yoshimoto et al. 1992, Dahia et al. 1995, Wang et al. 


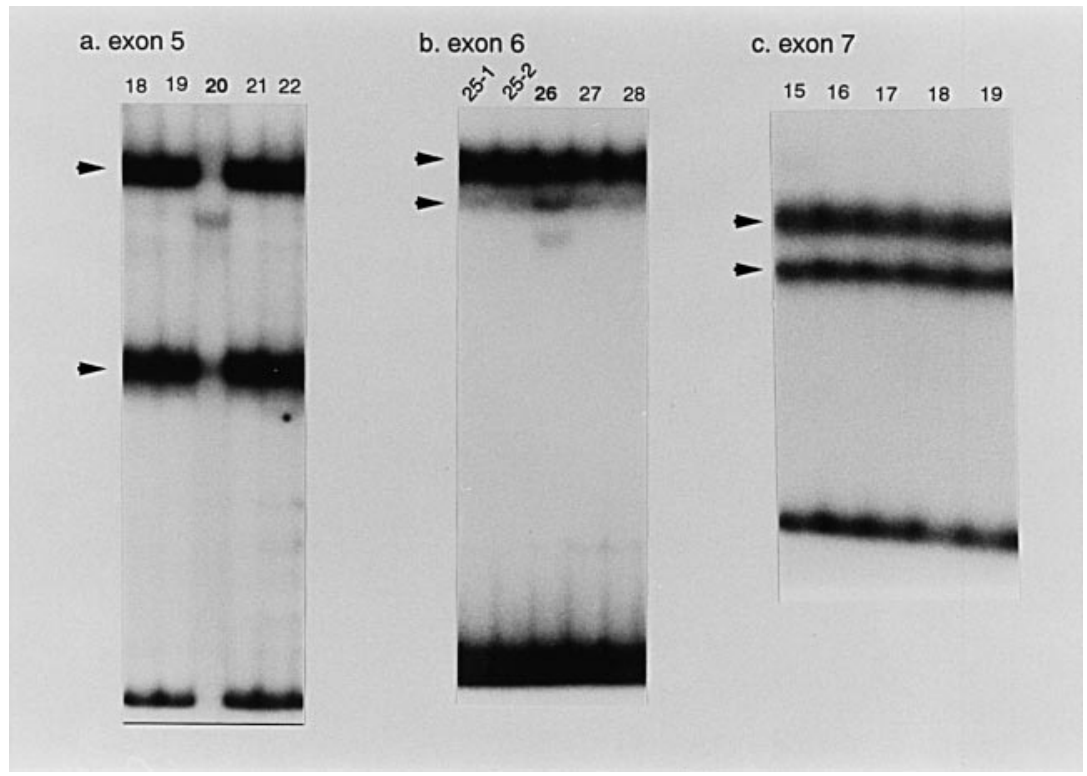

Figure 2 PCR-SSCP analysis of p53 gene mutation in (a) exon 5, (b) exon 6 and (c) exon 7 in phaeochromocytoma. Each arrow head represents the single stranded band observed after polyacrylamide gel electrophoresis. The lane number represents the specimen number from 32 cases of phaeochromocytoma. Bold characters indicate lanes with abnormal band-shifts.

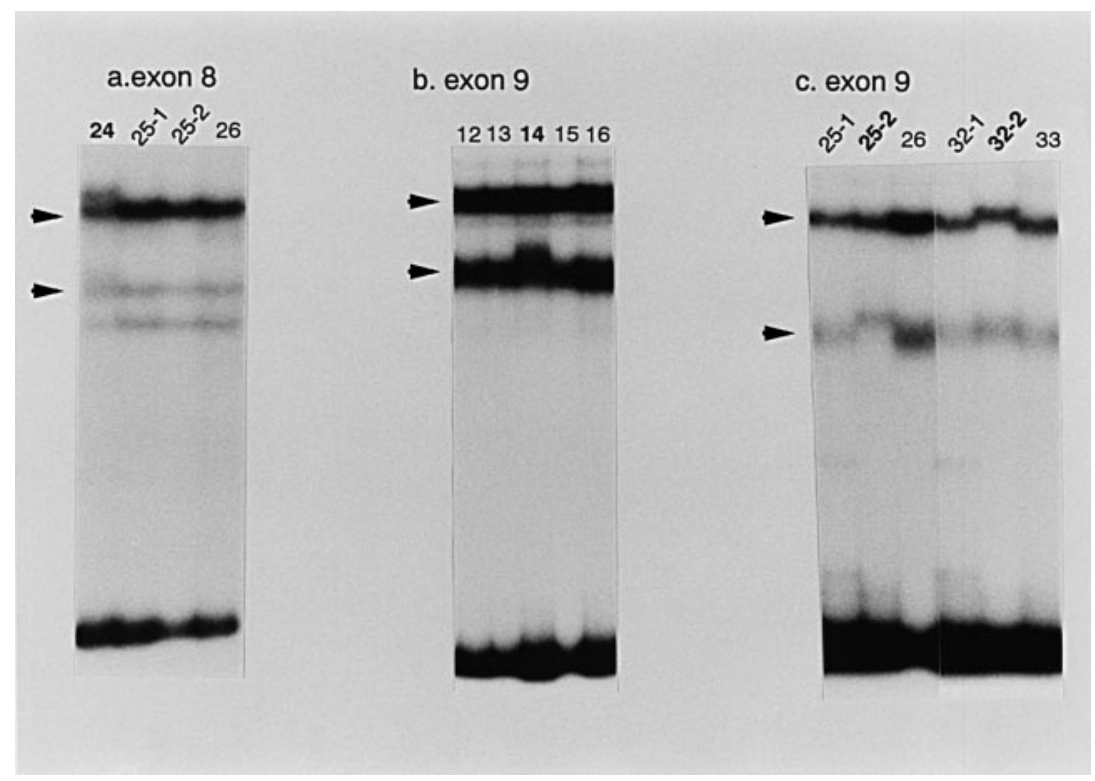

Figure 3 PCR-SSCP analysis of p53 gene mutation in (a) exon 8, and (b) and (c) exon 9 in phaeochromocytoma. Each arrow head represents the single stranded band observed after polyacrylamide gel electrophoresis. The lane number represents the specimen number from 32 cases of phaeochromocytoma. Bold characters indicate lanes with abnormal band-shifts.

1995), no p53 gene mutations were observed in 18 cases of benign solitary phaeochromocytoma. However, 2 of 5 benign multiple cases and 4 of 10 malignant cases did show p53 gene mutations or intronic sequence alterations. This suggests that p53 mutation or intronic sequence alteration in phaeochromocytoma may be confined exclusively to multiple or malignant cases. These results are also compatible with similar findings in adrenocortical carcinoma in 
Table 3 Spectrum of p53 gene mutation in phaeochromocytoma

\begin{tabular}{|c|c|c|c|c|c|c|c|}
\hline & Race & Type & Exon/intron & Nucleotide change & Amino acid & p53 IHC & p21/WAF1/Cip1 IHC \\
\hline \multicolumn{8}{|c|}{ Case no. } \\
\hline 14 & C & Malignant & Intron 8 & $\mathrm{C}$ to $\mathrm{T}(14676 \mathrm{nt})$ & No change & ND & ND \\
\hline 20 & $\mathrm{~J}$ & Benign multiple & Exon 5 & TGC to CGC (codon 135$)$ & Cys to Arg & Positive & Very weak \\
\hline \multirow[t]{3}{*}{$25-2$} & J & Malignant & Exon 9 & TCT to TTT (codon 315) & Ser to Phe & Positive & Very weak \\
\hline & & & Exon 9 & CCC to CCT (codon 309) & No change & & \\
\hline & & & Exon 9 & AGC to AGT (codon 313) & No change & & \\
\hline $32-2$ & $\mathrm{~J}$ & Malignant & Intron 9 & $\mathrm{C}$ to $\mathrm{T}(14771 \mathrm{nt})$ & No change & Positive & Very weak \\
\hline
\end{tabular}

C, Chinese; J, Japanese; nt, nucleotide; ND, not determined; IHC, immunohistochemistry.

which p53 gene mutations were found in approximately $25 \%$ of the patients (Greenblatt et al. 1994, Reincke et al. 1994).

Of the six cases of phaeochromocytoma with p53 gene mutations or intronic sequence alteration in our study, two cases (14 and 32-2) contained intronic sequence alterations and one case (25-2) had point mutations in exon 9 and a sequence alteration in intron 4 . Thus the positions of the mutations or sequence alterations were atypical when compared with previous findings which showed that in various types of neoplasma p53 gene mutations were clustered in exons 5 to 8 (Hollstein et al. 1991, Greenblatt et al. 1994, Velculescu \& El-Deiry 1996). In addition, we observed one case (24) where a point mutation in exon 8 did not lead to an amino acid change (i.e. a silent mutation). These results raise questions over the functional significance of $\mathrm{p} 53$ gene mutations or intronic sequence alterations in cases where the $\mathrm{p} 53$ gene product appears to be unaltered.

This issue was investigated by analyzing p53 protein levels. Since the half-life of wild-type $\mathrm{p} 53$ protein is several minutes, p53 protein levels in normal cells are relatively very low and generally undetectable by immunohistochemistry. However, abnormal p53 protein can be easily detected by immunohistochemistry because of the prolongation of its half-life (Greenblatt et al. 1994, Hall \& Lane 1994, Velculescu \& El-Deiry 1996). Immunohistochemical analysis for p53 protein was therefore performed on five of six phaeochromocytoma specimens with p53 gene mutations. As shown in Fig. 4 and Table 3, three of five specimens showed positive p53 immunostaining, suggesting an accumulation of abnormal p53 protein in the
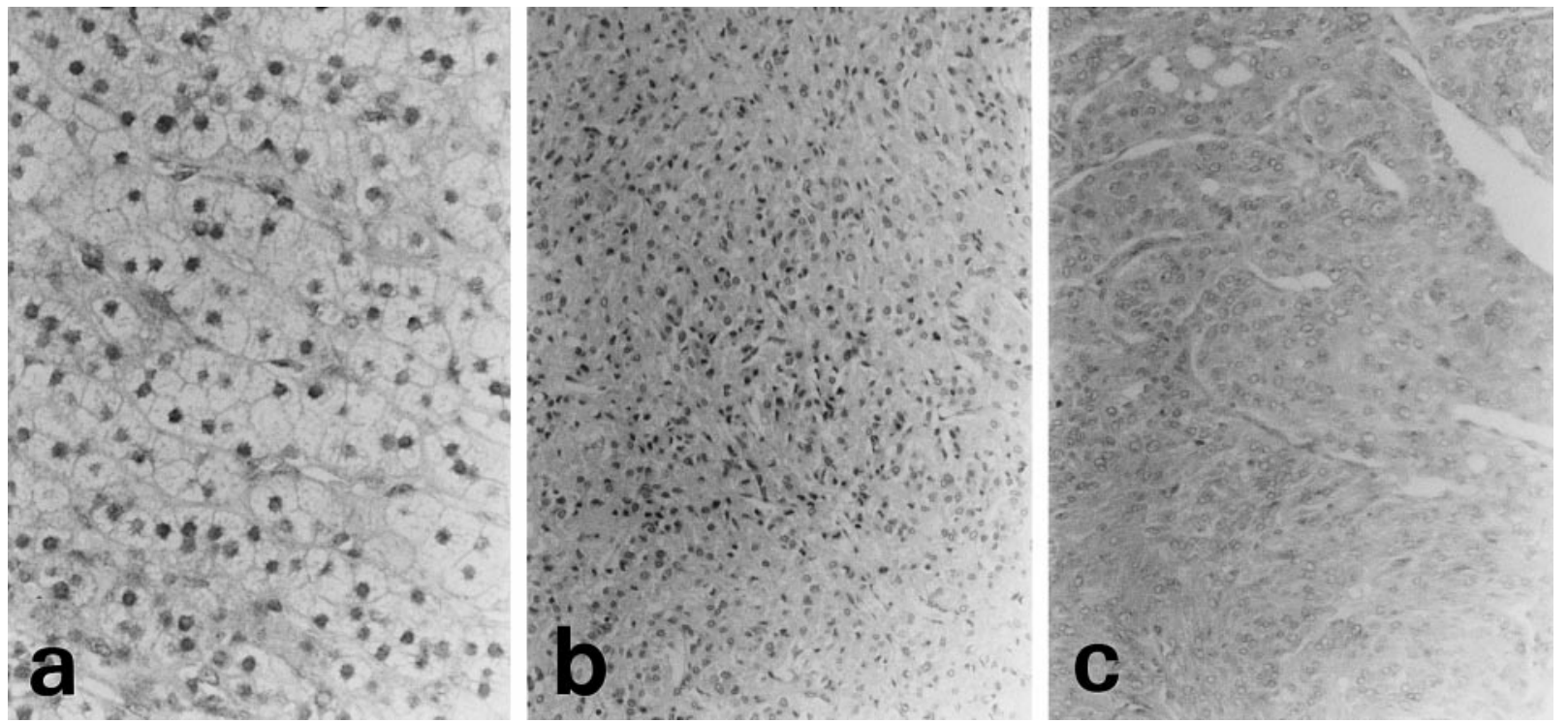

Figure 4 Immunohistochemical staining of p53 protein in phaeochromocytoma. Both case 20 (a) and case 32 (b) with p53 gene mutation or intronic sequence alteration showed over-expression of p53 protein in tumour cell nuclei. However, case 4 (c) without p53 gene mutation showed negative staining of p53 protein. 

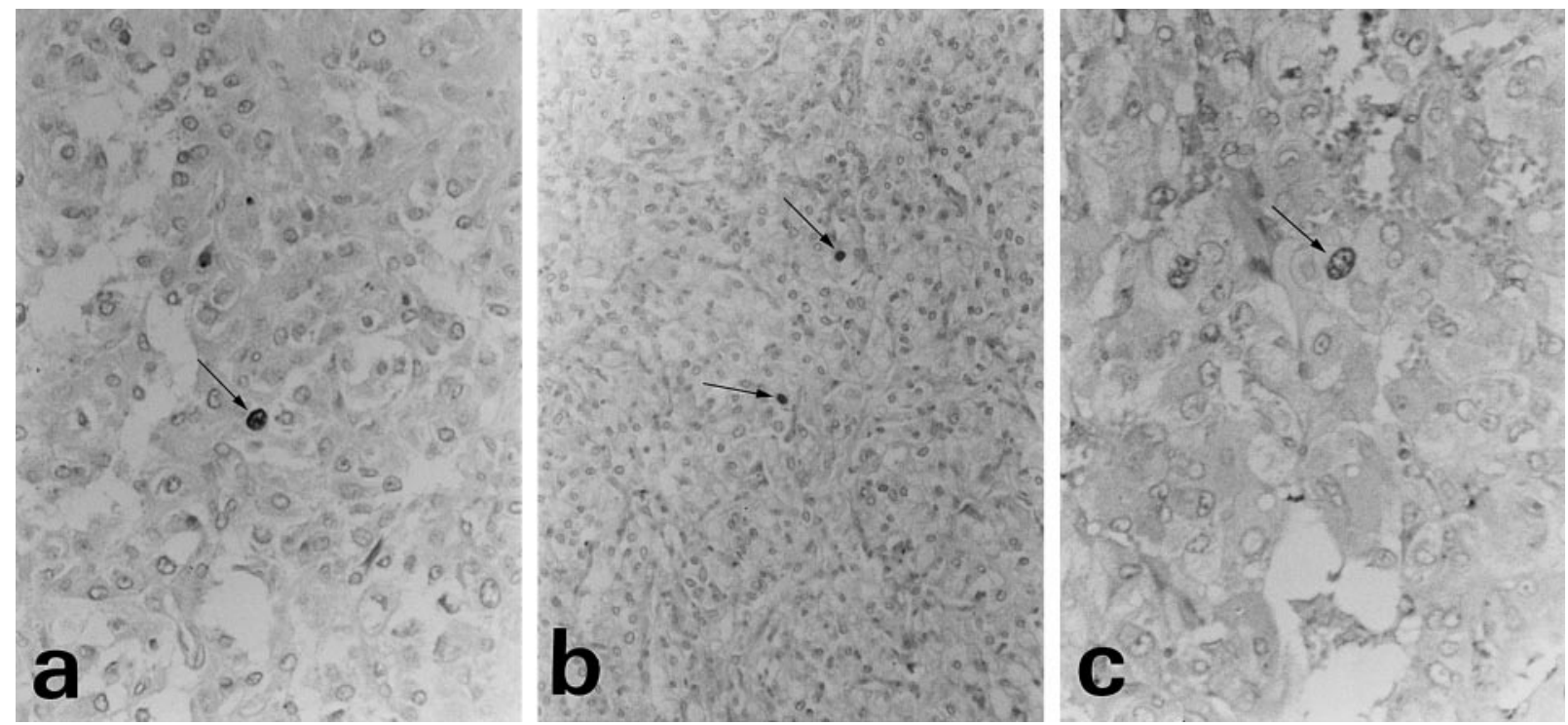

Figure 5 Immunohistochemical staining of p21/WAF1/Cip1 protein in phaeochromocytoma. (a) Case 26 with p53 gene mutation, but with negative staining of p53 protein. (b) Case 32 with p53 gene intronic sequence alteration and p53 over-expression. (c) Case 1 without p53 gene mutation. Regardless of p53 status, p21/WAF1/Cip1 was expressed faintly in the nuclei of scattered tumour cells in all specimens studied. Arrows indicate positive immunostaining of the tumour cell nuclei.

tumour cells. One of the two specimens that showed negative immunostaining of p53 (case 24) contained the silent mutation in exon 8 . The other case showed missense mutation of codon 190 in exon 6, which is outside the highly conserved domain of p53 (Hollstein et al. 1991, Greenblatt et al. 1994). Interestingly, abnormal accumulation of p53 protein was observed in case 32-2 that contained a sequence alteration in intron 9. It is possible to assume that in this case abnormal splicing may lead to an aberrant $\mathrm{p} 53$ protein, or that there may be some mutations in coding exons 2, 3, 10 and 11. In contrast, we could not detect any abnormal immunostaining of p53 in five benign solitary phaeochromocytoma specimens without p53 gene mutations. These results agree with the report of Wang et al. (1995) that showed no abnormal p53 immunostaining in 24 phaeochromocytoma specimens.

The results of PCR-SSCP followed by direct DNA sequencing and immunohistochemistry demonstrated p53 gene mutations or intronic sequence alterations associated with abnormal accumulation of $\mathrm{p} 53$ protein phaeochromocytoma tissues from multiple and malignant cases. Since p53 is closely related to various proteins regulating the cell cycle (Velculescu \& El-Deiry 1996), abnormal p53 function may cause accelerated cell proliferation leading to multicentric tumorgenesis and/or malignant tumour. However, $60 \%$ of multiple and malignant cases showed no mutations of the $\mathrm{p} 53$ gene. This suggests that $\mathrm{p} 53$ gene mutations are not a necessity for the development of multiple and/or malignant phaeochromocytomas. In cases 25 and 32, p53 gene mutations or intronic sequence alterations were identified only in the second specimens
(25-2, 32-2) obtained by autopsy when the patients died of malignant phaeochromocytoma with multiple bone metastasis, but not in the first specimens $(25-1,32-1)$ obtained by surgical removal of the adrenal tumour when they were considered to be benign solitary tumours. Thus p53 gene mutation or intronic sequence alteration appears to be a characteristic of tumour agressiveness during the later phase of multiple and/or malignant phaeochromocytoma. However, considering its high specificity, p53 gene mutation or intronic sequence alteration could be a useful marker in detecting multiple or malignant phaeochromocytomas.

In the present study, five of six phaeochromocytoma cases with p53 point mutations or intronic sequence alterations showed the $\mathrm{G}: \mathrm{C}$ to $\mathrm{A}: \mathrm{T}$ transition mutations. Since the types of mutations observed in the p53 gene are known to depend on the tumour type (Hollstein et al. 1991, Greenblatt et al. 1994, Velculescu \& El-Deiry 1996), the transition mutations found in this study may be characteristic of multiple or malignant phaeochromocytomas. In agreement with our results, Lin et al. (1994) reported the same type of transition in two of four p53 point mutations in phaeochromocytomas. However, they also reported that the other two point mutations were G:C to $\mathrm{C}: \mathrm{G}$ transversions, which are less common in the mutational spectrum of human cancers (Greenblatt et al. 1994). Both geographic and ethnic factors have been shown to affect the mutational spectrum of $\mathrm{p} 53$ in various tumours (Greenblatt et al. 1994) and may be at least partly responsible for the difference between our results and those of Lin et al. (1994). 
In the present study, we observed poor expression of p21/WAF1/Cip1 in all the phaeochromocytoma tissues regardless of the presence or absence of p53 mutation, showing no correlation between them. The results are in agreement with the previous studies in which no correlation between p21/WAF1/Cip1 expression and p53 expression or $\mathrm{p} 53$ mutational status was demonstrated in various tumours (Barbareschi et al. 1996, Marchetti et al. 1996, Slebos et al. 1996). The apparently high incidence of p53 gene sequence alteration in benign multifocal tumour $(2 / 5)$ and malignant case (4/10) compared with benign solitary tumour (phaeochromocytoma: $0 / 18$; adrenocortical tumour: 0/29) and positive p53 immunostaining suggest that alteration of the DNA sequence in these cases is mutation rather than simple rare polymorphism. However, since it was not feasible to compare the results of DNA sequences in phaeochromocytomas with those in normal adrenal medulla, the possibility that the observed sequence alteration may be a rare polymorphism could not be excluded completely.

In conclusion, a relatively high incidence of p53 gene mutation or intronic sequence alteration was found in cases of multiple or malignant phaeochromocytoma, while no such gene mutation was found in cases of benign solitary phaeochromocytoma and adrenocortical adenoma of primary aldosteronism and Cushing's syndrome. The results suggest a pathophysiological significance of p53 gene mutations in the development of some multiple and malignant phaeochromocytomas.

\section{Acknowledgements}

We thank Ms Y Tabei (Department of Medicine, Institute of Clinical Endocrinology, Tokyo Women's Medical College) for her continuous support. This work was supported in part by research grants from the Japanese Ministry of Health and Welfare 'Disorders of Adrenal Hormones' Research Committee, the Research Fellowships of the Japan Society for the Promotion of Science for Young Scientists, research grants from the Japanese Ministry of Education, Science, and Culture, and a research grant from Tanabe Biomedical Conference (Tokyo).

\section{References}

Barbareschi M, Caffo O, Doglioni C, Fina P, Marchetti A, Buttitta F, Leek R, Morelli L, Leonardi E, Bevilacqua G, Dalla Palma P \& Harris AL 1996 p21WAF1 immunohistochemical expression in breast carcinoma: correlation with clinicopathological data, oestrogen receptor status, MIB1 expression, p53 gene and protein alteration and relapse-free survival. British Journal of Cancer 74 208-215.

Buchman VL, Chumakov PM \& Georgiev GP 1988 A variation in the structure of the protein-coding region of the human p53 gene. Gene 70 245-252.
Dahia PLM, Aguiar RCT, Tsanaclis AM, Bendit I, Bydlowski SP, Abelin NMA \& Toledo SPA 1995 Molecular and immunohistochemical analysis of p53 in phaeochromocytoma. British Journal of Cancer 72 1211-1213.

El-Deiry WS, Tokino T, Waldman T, Oliner JD, Velculescu VE, Burrell M, Hill DE, Healy E, Rees JL, Hamilton SR, Kinzler KW \& Vogelstein B 1995 Topological control of p21WAF1/CIP1 expression in normal and neoplastic tissues. Cancer Research $\mathbf{5 5}$ 2910-2919.

Futreal PA, Barrett JC \& Wiseman RW 1991 An Alu polymorphism intragenic to the TP53 gene. Nucleic Acids Research 196977.

Greenblatt MS, Bennett WP, Hollstein M \& Harris CC 1994 Mutation in the p53 tumor supressor gene: clues to cancer etiology and molecular pathogenesis. Cancer Research 54 4855-4878.

Hall PA \& Lane DP 1994 p53 in tumor pathology: can we trust immunohistochemistry? - revisited. Journal of Pathology 172 1-4.

Hollstein M, Sidransky D, Vogelstein B \& Harris CC 1991 p53 mutations in human cancers. Science 235 49-53.

Khosla S, Patel VM, Hay ID, Schaid DJ, Grant CS, Van Heerden JA \& Thibodeau 1991 Loss of heterozygosity suggests multiple genetic alterations in pheochromocytomas and medullary thyroid carcinomas. Journal of Clinical Investigation 87 1691-1699.

Landsberg L \& Young JB 1992 Catecholamines and the adrenal medulla. In Williams Textbook of Endocrinology, edn 8, pp 621-705. Eds JD Wilson \& DW Foster. Philadelphia: Saunders.

Lin SR, Lee YJ \& Tsai JH 1994 Mutations of the p53 gene in human functional adrenal neoplasms. Journal of Clinical Endocrinology and Metabolism 78 483-491.

Marchetti A, Doglioni C, Barbareschi M, Buttitta F, Pellegrini S, Bertacca G, Chella A, Merlo G, Angeletti CA, Palma PD \& Bevilacqua G 1996 p21 RNA and protein expression in non-small cell lung carcinomas: evidence of p53-independent expression and association with tumoral differentiation. Oncogene 12 1319-1324.

Orth DN, Kovacs WJ \& DeBold CR 1992 The adrenal cortex. In Williams Textbook of Endocrinology, edn 8, pp 489-621. Eds JD Wilson \& DW Foster. Philadelphia: Saunders.

Reincke M, Karl M, Travis WH, Mastorakos G, Allolio B, Linehan HM \& Chrousos GP 1994 p53 mutations in human adrenocortical neoplasms: immunohistochemical and molecular studies. Journal of Clinical Endocrinology and Metabolism 78 790-794.

Reincke M, Wachenfeld C, Mora P, Thumser A, Jaursch-Hancke C, Abdelhamid S, Chrousos GP \& Allolio B 1996 p53 mutations in adrenal tumors: Caucasian patients do not show the exon 4 'hot spot' found in Taiwan. Journal of Clinical Endocrinology and Metabolism 81 3636-3638.

Sambrook J, Fritsch EF \& Maniatis T 1989 Molecular Cloning. A Laboratory Manual, edn 2, pp 6·30-6.31. New York: Cold Spring Harbor Laboratory Press.

Slebos RJ, Baas IO, Clement M, Polak M, Mulder JW, van den Berg FM, Hamilton SR \& Offerhaus GJ 1996 Clinical and pathological association with p53 tumor-suppressor gene mutations and expression of $\mathrm{p} 21 \mathrm{WAF} 1 / \mathrm{CIP} 1$ in colorectal carcinoma. British Journal of Cancer 74 165-171.

Velculescu VE \& El-Deiry WS 1996 Biological and clinical importance of the p53 tumor supressor gene. Clinical Chemistry 42 858-868.

Vojtesek B, Bartek J, Midgley CA \& Lane DP 1992 An immunochemical analysis of the human nuclear phosphoprotein p53: new monoclonal antibodies and epitope mapping using recombinant $\mathrm{p} 53$. Journal of Immunological Methods 151 237-244.

Wang DG, Johnston CF, Anderson N, Sloan JM \& Buchanan KD 1995 Overexpression of the tumour suppressor gene p53 is not implicated in neuroendocrine tumour carcinogenesis. Journal of Pathology 175 397-401.

Yana I, Nakamura T, Shin E, Karakawa K, Kurahashi H, Kurita Y, Kobayashi T, Mori T, Nishisho I \& Takai S 1992 Inactivation of 
the p53 gene is not required for tumorgenesis of medullary thyroid carcinoma or pheochromocytoma. Japanese Journal of Cancer Research 83 1113-1116.

Yano T, Linehan M, Anglard P, Lerman MI, Daniel LN, Stein CA, Robertson CN, LaRocca R \& Zbar B 1989 Genetic changes in human adrenocortical carcinoma. Journal of the National Cancer Institute 81 518-523.
Yoshimoto K, Iwahana H, Fukuda A, Sano T, Saito S \& Itakura M 1992 Role of p53 mutations in endocrine tumorgenesis: mutation detection by polymerase chain reaction-single strand conformation polymorphism. Cancer Research 52 5061-5064.

Received 23 April 1998

Accepted 23 June 1998 